\title{
Preliminary study on the tea dust explosion: the effect of tea dust size
}

\author{
Nur Hikmah Semawi ${ }^{1}$, Siti Zubaidah Sulaiman ${ }^{1, *}$, Noor Sabrina Ahmad Mutamim ${ }^{1}$, Siti Kholijah Abdul Mudalip ${ }^{1}$, \\ Rohaida Che Man ${ }^{1}$, Shalyda Md Shaarani ${ }^{1}$, Zatul Iffah Mohd Arshad ${ }^{1}$, Hayder A Abdul Bari ${ }^{1}$ and Rafiziana Md \\ Kasmani $^{2}$ \\ ${ }^{1}$ Faculty of Chemical and Natural Resources Engineering, Universiti Malaysia Pahang, 26300 Kuantan, Pahang, Malaysia \\ ${ }^{2}$ Faculty of Chemical Engineering, Universiti Teknologi Malaysia, 81310 Skudai, Johor, Malaysia
}

\begin{abstract}
Food-based dust is considered as combustible dust as they composed of distinct particles, regardless of the size or chemical composition and when suspended in air or any other oxidizing medium over a range of concentrations will present a fire or deflagration hazard. The explosion effect from food-based dust can cause catastrophic consequences because the initial shock wave from the explosion lift up more dust and triggers a chain reaction through the plant. One of the parameters that can enhance the explosion is the particle size of the dust. In this study, the effect of four different particle sizes of tea dust on the dust explosion severity was tested in a confined $20 \mathrm{~L}$ explosion bomb. Tea dust tends to explode due to its molecular structure which contains a carbon-hydrogen bond that can release the significant amount of thermal energy. The experimental results showed that the values of $P_{\max }$ and $(\mathrm{dP} / \mathrm{dt})_{\max }$ of tea dust were more severe for the particle size of $160 \mu \mathrm{m}$ for which are $1.97 \mathrm{bar}$ and $4.97 \mathrm{bar} / \mathrm{s}$ before drying and 2.09 bar and $7.01 \mathrm{bar} / \mathrm{s}$ after drying process. The finer dust reacted more violently than coarser ones. As particle size decreases, the rate of explosion pressure change increases, as long as the size is capable of supporting combustion.
\end{abstract}

Combustible dust explosions have caused several large property losses at industrial plants in the past decade. A wide variety of materials that can be explosible in dust form exist in many industries such as food, grain, tobacco, wood, plastics, pulp, paper, rubber, pharmaceuticals, pesticides, dyes, coal and metals. These materials are used in a wide range of industries and processes and may also occur naturally such as from pollens, volcanic ashes and sandstorms. The mechanisms that create dust and keep it suspended in air emerge from aerodynamic forces. Then it will be carried away to another place as a result of air currents. Combustible dust is fine particles that present an explosion hazard or a blast risk when suspended in air under specific conditions. As defined by the National Fire Protection
Association (NFPA) [1], combustible dust is characterized as a combustible particulate solid that exhibits a fire or deflagration hazard when suspended in air, or some other oxidizing medium, over a range of concentrations, regardless of particle size and shape.

In dust explosion studies, the focus has been mainly on dust explosion mechanisms and preventative safety measures on carbonaceous and metal dust explosion. However, agricultural dust explosion, especially in the food and beverage industries, is seldom seen. Furthermore, many people did not know food-based such as flour, grain, sugar, coffee, tea, and spices are among highly combustible dust. Under the right conditions, table sugar can be as flammable as wood; which is made of cellulose or lots of sugar molecules linked together.

\footnotetext{
*Corresponding author: szubaidah@ump.edu.my
} 
According to Yan and $\mathrm{Yu}$ [2] these particles are much more flammable because of their surface area-to-volume ratio. Taveau [3] said a primary dust explosion, which usually followed by a secondary explosion, will lead to serious damage to nearby units. The overpressure and flames from primary explosion play an important role in triggering a secondary explosion.

Tea was originated in South Eastern China and nowadays it is cultivated in many countries all over the world and has more than 82 different species. Adnan et al. [4] stated that the chemical components in tea include amino acids, polysaccharides, volatile acids, vitamins, lipids, alkaloids (theobromine, caffeine, and theophylline), polyphenols (catechins and flavonoids) as well as inorganic elements. Furthermore, during photosynthesis, plants store energy in the form of starches and sugars, also known as carbohydrates. Plants later use this stored energy to fuel important reactions. In tea, the enzymatic reactions that occur during oxidation are fuelled by the carbohydrates and additionally, they are responsible for the formation of polyphenols in young tea leaves.

During the processing of tea dust, much dust is generated and it leads to a dust explosion hazard. The explosion effect from food-based dust can cause catastrophic consequences because the initial shock wave from the explosion lift up more dust and triggers a chain reaction through the plant. As the result, there are mass destruction of pieces of equipment and buildings, as well as causing possible death or injury to employees. In order to prevent such accident, Proust et al., Dufaud et al. and Dobashi [5-7] stated that the chemical property of the dust, the dust explosion sensitivity parameter such as the particle size and the dust explosion severity characteristics which are the maximum explosion pressure $\left(\mathrm{P}_{\max }\right)$, rate of pressure rise $(\mathrm{dP} / \mathrm{dt})$ and dust deflagration index $\left(\mathrm{K}_{\mathrm{St}}\right)$ are necessary required. Thus, in this paper, the chemical properties of tea and the explosion severity analysis were studied.

\subsection{Sample preparation}

The sample used in this research was tea dust which can be purchased from local stores and the selection was done on the basis of brand popularity. The samples were ground by using a high-performance laboratory blender. After the grinding process, the samples were sieved into four different sizes which were $125 \mu \mathrm{m}, 160 \mu \mathrm{m}, 180 \mu \mathrm{m}$ and $220 \mu \mathrm{m}$. Upon testing, the samples would be dried at a temperature of $105{ }^{\circ} \mathrm{C}$ in an oven for one hour to get rid of the moisture [4].

\subsection{Experimental equipment and methodology}

\subsubsection{Chemical properties identification: analysis by thermogravimetry (TGA)}

The equipment is used in order to measure the amount and the rate of change of weight of material as a function of temperature or time in a controlled atmosphere. First, $5 \mathrm{mg}$ of sample was weighed in a platinum pan. Next, the programme of ramping was chosen and the sample was heated at a heating ramp of $10^{\circ} \mathrm{C}$ per minute until the temperature reached $900{ }^{\circ} \mathrm{C}$. The components are calculated based on the specific temperature i.e. for moisture content, $\mathrm{T}=105^{\circ} \mathrm{C}$, volatility, $\mathrm{T}=500{ }^{\circ} \mathrm{C}$ and fixed carbon $\mathrm{T}=600^{\circ} \mathrm{C}$ while ash was determined as the residual. The following equations were used to analyze the mass loss and the differential loss.

$$
\begin{gathered}
\% \text { of Moisture }=\left(\mathrm{W}-\mathrm{W}_{105}\right) / \mathrm{W} \times 100 \% \\
\% \text { of Ash }=\mathrm{W}_{600} / \mathrm{W} \times 100 \% \\
\% \text { of Volatility }=\left(\mathrm{W}_{105}-\mathrm{W}_{500}\right) / \mathrm{W} \times 100 \% \\
\% \text { of Fixed Carbon }=\left(\mathrm{W}_{500}-\mathrm{W}_{600}\right) / \mathrm{W} \times 100 \%
\end{gathered}
$$

Where $\mathrm{W}$ is the initial mass of the sample $(\mathrm{mg}), \mathrm{W}_{105}$, $\mathrm{W}_{500}$ and $\mathrm{W}_{600}$ are the mass of the sample at the temperature of $105^{\circ} \mathrm{C}, 500{ }^{\circ} \mathrm{C}$ and $600{ }^{\circ} \mathrm{C}$ respectively.

\subsubsection{Analysis of explosion data}

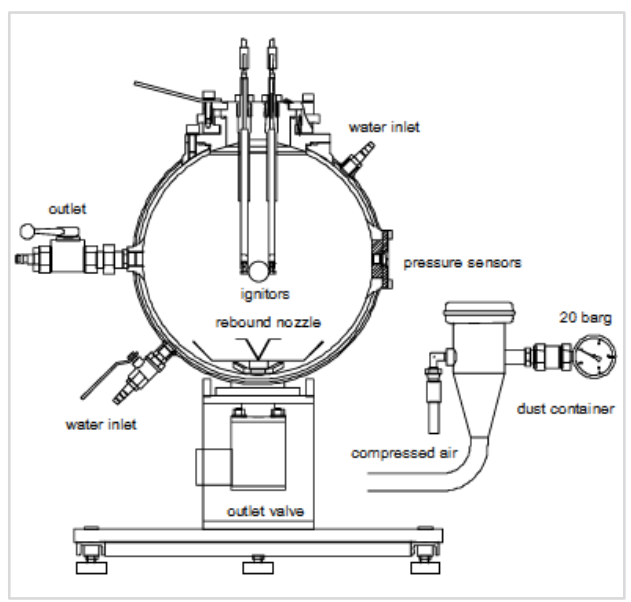

Fig. 1. Schematic diagram of Siwek 20 L spherical vessel [8]

$20 \mathrm{~L}$ spherical vessel as shown in Figure 1 was used to obtain the flammability and severity data. The explosion experiments were performed by using two $5 \mathrm{~kJ}$ chemical igniters as the standard ignition source that were connected to the ignition leads. The ignition delay time, $\mathrm{t}_{\mathrm{v}}$ was fixed at $60 \mathrm{~ms}$. The pressure inside the spherical vessel was measured by two "Kistler" piezoelectric pressure sensors. The dust was loaded directly to the storage container and were dispersed with the rebound nozzle connected to an outlet valve located at the bottom of the vessel by using compressed air pressurized at 20 bar (gauge). The vessel was interfaced with a computer, which controls the dispersion or firing sequence and data collection by using the control system named KSEP. As part of the experimental programme, three repeat tests were performed on each test and these demonstrated 
good reproducibility, with peak pressures varying by less than $\pm 5 \%$ in magnitude.

\section{Results and discussion}

\subsection{Chemical properties identification: moisture content, volatility, fixed carbon and ash}

Thermogravimetry (TGA) method based on ASTM (2008) procedure was applied to determine the explosion severity characteristics of the tea dust. The percentage of weight loss of the four different sizes of tea dust can be calculated from the TGA curves. From the data obtained, the chemical parameters such as moisture, volatility, fixed carbon and ash content can be determined. Particle size distribution plays a significant role in the flame propagation process. It is the dominant physical parameter that affects explosion severity and ease of ignition for combustible dust [8]. Benedetto et al. [9] suggested that when coarser particles exist, devolatilization and particle heating could control the explosion process. Table 1 shows the results obtained from TGA.

Table 1. Chemical properties of tea dust

\begin{tabular}{|l|l|l|l|l|}
\hline $\begin{array}{l}\text { Size } \\
(\boldsymbol{\mu m})\end{array}$ & $\begin{array}{l}\text { Moisture } \\
(\mathbf{\%})\end{array}$ & $\begin{array}{l}\text { Volatility } \\
(\mathbf{\%})\end{array}$ & $\begin{array}{l}\text { Fixed } \\
\text { carbon } \\
(\mathbf{\%})\end{array}$ & $\begin{array}{l}\text { Ash } \\
(\mathbf{\%})\end{array}$ \\
\hline 125 & 8.87 & 60.51 & 25.92 & 5.09 \\
\hline 160 & 9.08 & 56.30 & 30.46 & 5.41 \\
\hline 180 & 10.52 & 53.37 & 3.08 & 22.73 \\
\hline 220 & 13.54 & 51.23 & 4.04 & 23.18 \\
\hline
\end{tabular}

As shown in Table 1, the moisture content was the highest for the size of $220 \mu \mathrm{m}$ followed by the size of $180 \mu \mathrm{m}, 160 \mu \mathrm{m}$ and $125 \mu \mathrm{m}$. Tea dusts tend to absorb air moisture and a layer of water molecules will form on the particle surface. This layer causes the particle to agglomerate, and increase the virtual particle size and reduce the surface area. It can be concluded that the greater the particle size will have higher the moisture content. With the increase of moisture content, the ignition sensitivity of dust weakens significantly, and the lower heat value of dust reduces linearly. Wade et al. and Du et al. [10,11] suggested that he energy of an ignition source was absorbed by the water in the particles. Consequently, the maximum explosion pressure and the rate of pressure rise decrease with the rise of moisture content.

Another parameter obtained from Table 1 is the volatility of tea dust. Based on Table 1, it shows the volatility of tea decreases as the size increases. As stated by Abbasi and Abbasi [12], in dust explosion mechanism, the smaller the particle size of the dust, the more volatiles are expelled. The measurement of the volatile content by TGA is a slow heating process. It is possible that under fast heating in a flame front, the carbon is converted to $\mathrm{CO}$ and adds to the volatiles. It was also found that the volatile release activation energy increased with the content of water and ash in the tea. Devolatilization and particle heating could control the explosion process when coarser particles existed as mentioned by Todaka et al. [13]. The more volatile the dust, the smaller the value of heat is needed to ignite the dust/air mixture. Lower flammability limit coincided well with the conditions when the mass density of smaller particles was above the limit.

Besides, Table 1 also shows the fixed carbon of tea dust. Fixed carbon is the solid flammable residue that remains once the particle is heated and the volatile matter is removed. The value was calculated from the difference between 100 and the sum of the moisture, volatile matter and ash. The TGA result showed that the fixed carbon of tea dust ranging from 3 to $30 \mathrm{wt} \%$. From Table 1, the particle size of $160 \mu \mathrm{m}$ has the highest value of fixed carbon which is $30.46 \%$ and this might be due to the greater surface area of the particle and the content of the moisture, volatile matter and ash of the sample.

The last parameter obtained from Table 1 is the ash content. Ash is the residue remaining after water and organic matter has been removed by a heating process with the presence of oxidizing agents. Cashdollar, Fumagalli et al. and Bershad $[14,15,16]$ mentioned the ash present in the dust sample is a measure of the inorganic material content and it also represents the fraction which is incombustible. Based on Table 1, the ash content increases as the particle size increases. The higher the ash content might be due to the less moisture content in the sample [15]. By absorption process or thermal energy released from combustion reaction, ash which is incombustible may act as inertant [16], and it does not affect the combustion and explosion. From these results, it can be concluded that as the particle size increases, the moisture content and ash content also increase while the volatility decreases.

\subsection{Tea dust explosion characteristics}

\subsubsection{Maximum explosion overpressure $\left(P_{\max }\right)$ of tea dust}

In order to identify the explosion characteristics of tea dust, the tea dust was tested and performed within a $20 \mathrm{~L}$ vessel. Figure 2 shows the $\mathrm{P}_{\max }$ function of time. The value is one of the explosive properties estimated within the experiment to measure the severity of a dust explosion. It measures the maximum explosion overpressure generated in the test vessel. 


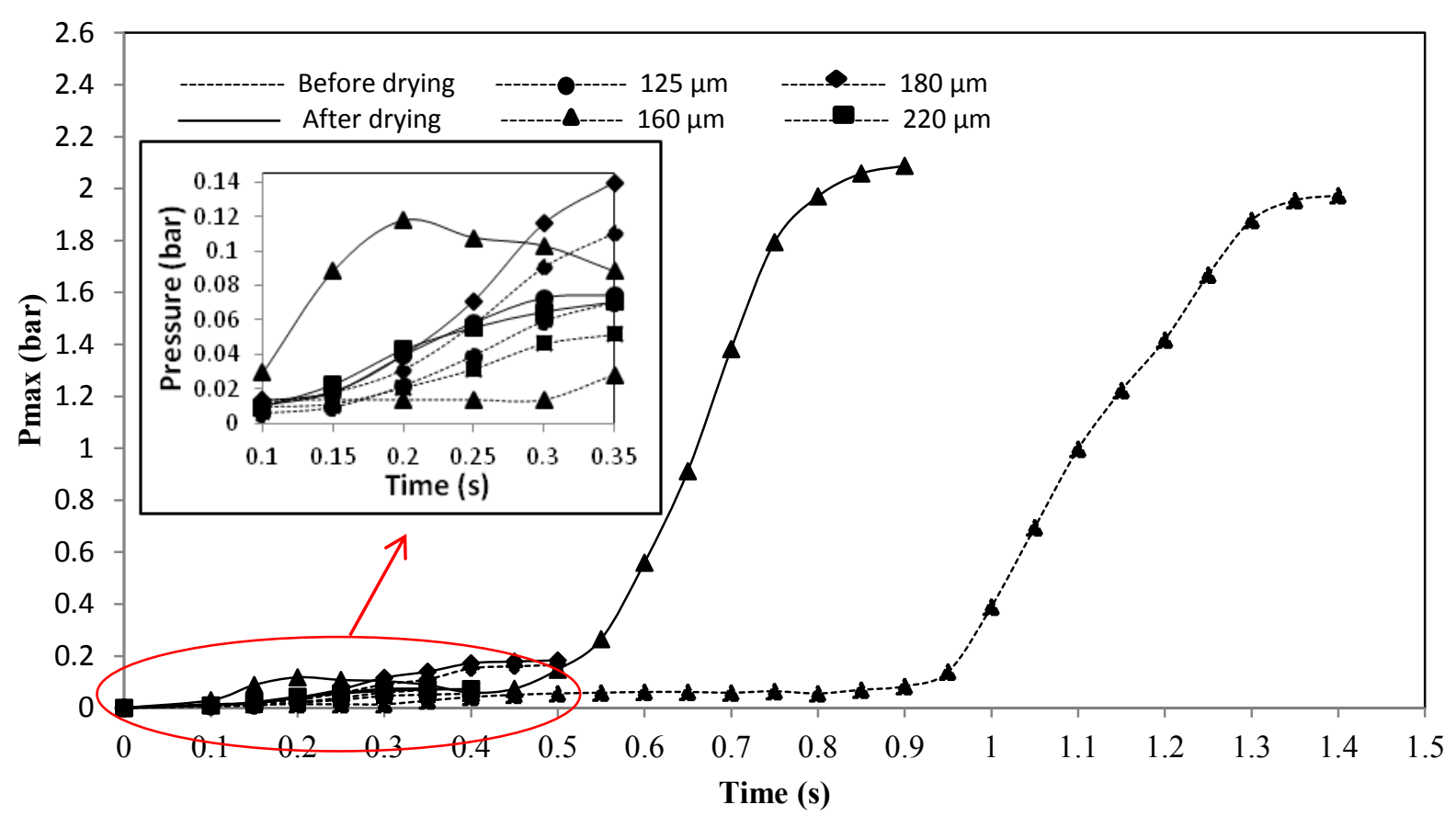

Fig. 2. Graph of $P_{\max }$ versus time

Based on Figure 2, all dust sizes start to ignite at $\mathrm{t}=$ 0.1 s. A slow combustion was performed for all dust sizes. After a few milliseconds, the combustion turns fast due to the flame acceleration as the mass burning rate increase. However, the particle size of $160 \mu \mathrm{m}$ takes the longest time to complete the combustion and explosion which is about $1.4 \mathrm{~s}$ before and $0.9 \mathrm{~s}$ after drying.

According to Lemkowitz et al. [17], a flammable mixture in a closed vessel undergoing deflagration and ignited in the centre, the flame expands spherically from the centre of the vessel until it reaches the wall. During this process, the pressure in the vessel continuously rises. Both the pressure and the rate of pressure rise reach a maximum when the flame reaches the wall of the vessel. From Figure 2, $\mathrm{P}_{\max }$ for particle size $125 \mu \mathrm{m}-220 \mu \mathrm{m}$ before drying are ranging from 0.07 bar -1.97 bar. After the drying process, the $\mathrm{P}_{\max }$ for all sizes is found to be increased by $6.16 \%, 5.94 \%, 10.20 \%$ and $30.09 \%$, respectively. From the results, the particle size of 160 $\mu \mathrm{m}$ shows the highest value of $\mathrm{P}_{\max }$ for both before and after the drying process which is 1.97 bar and 2.09 bar. As discussed by Lemkowitz and Pasman [18], the behaviour of the dust explosion strongly depends on the particle size. When the particle size decreases, the minimum energy required igniting the dust cloud decreases and thus the $\mathrm{P}_{\max }$ will increase. Lee et al. [19] also suggested that $\mathrm{P}_{\max }$ could increase with the decreasing of the particle size and the moisture content. Inoka et al. [20] convinced that the dispersibility of the dust increased as its moisture content decrease. A smaller particle size has a larger surface area and lower moisture content. The moisture content can reduce the amount of static electricity needed for ignition which makes the larger size dust which is $180 \mu \mathrm{m}$ and $220 \mu \mathrm{m}$ more difficult to ignite. This is shown in Figure 2, where
$\mathrm{P}_{\max }$ values decline slowly with increasing of particle size.

The size of the particles has a large influence on velocity and acceleration. The particle with smaller size and larger surface area are more ready to absorb heat and rapidly form ignitable mixtures. Based on the research done by Suhaimi et al. [21], the mass burning rate will speed up the flame propagation and result in the highest and steepest explosion overpressure development which represents the pressure versus time curves as shown in Figure 2. From Figure 2, the particle size of $160 \mu \mathrm{m}$ shows the significant steep rising from 0.08 bar to 1.95 bar before drying and 0.07 bar to 1.97 bar after drying. The burning rate for the particle size of $180 \mu \mathrm{m}$ and 220 $\mu \mathrm{m}$ are slow due to the higher moisture content of the dust.

\subsubsection{Maximum Rate of Pressure Rise $(d P / d t)_{\max }$}

From Figure 3, $(\mathrm{dP} / \mathrm{dt})_{\max }$ before drying for particle size $125 \mu \mathrm{m}-220 \mu \mathrm{m}$ before drying are ranging between $0.21 \mathrm{bar} / \mathrm{s}-4.97 \mathrm{bar} / \mathrm{s}$. After drying, $(\mathrm{dP} / \mathrm{dt})_{\max }$ increases to $1.4 \mathrm{bar} / \mathrm{s}, 7.01 \mathrm{bar} / \mathrm{s}, 4.63 \mathrm{bar} / \mathrm{s}$ and $2.78 \mathrm{bar} / \mathrm{s}$, respectively. From the results obtained in Figure 3, it shows that $(\mathrm{dP} / \mathrm{dt})_{\max }$ decreases as the particle size increases. This might be due to the distribution of the particle size. Particulates with a similar average particle size typically have a different particle size distribution. Dahoe et al. [22] stated that dust with exactly the same chemical composition, but with a smaller particle size distribution around the same median size may not explode at all under the standard test conditions. However, the same dust with a greater particle size 
distribution may result in a high explosion severity and sensitivity. This is because that the dust contains a significant fine fraction is more sensitive to ignition than the coarse fraction. Based on Dobashi [7], the particles may have irregular shapes which result in a larger surface area than the sphere with the same volume which makes the dust more explosive. Also, the larger particle size has a higher moisture content which increase the ignition energy and reduce the $(\mathrm{dP} / \mathrm{dt})_{\max }$ value.

For flame propagation mechanism, Cashdollar [14] indicates that a smaller particle size is likely to react faster than a larger particle size of the same material. Furthermore, the smaller particles are more easily to disperse and remain airborne longer, which is why the particle size of $160 \mu \mathrm{m}$ gives the highest $(\mathrm{dP} / \mathrm{dt})_{\max }$ compared to other sizes. The particle shape and porosity can also affect the surface area and reaction rate. The shapes with the greater surface area will propagate flame more readily and thus more hazardous.

Ramírez et al. [23] also indicate that the speed of particle combustion $(\mathrm{dP} / \mathrm{dt})_{\max }$. A faster and stronger explosion also can be created by a smaller particulate since this greatly will increase the value of $(\mathrm{dP} / \mathrm{dt})_{\max }$. It may also result in a more powerful pressure wave since it represents how much pressure developed within a second. Based on Figure 3, the particle size of $160 \mu \mathrm{m}$ showed the highest rate of pressure rise for before and after the drying process. Although the smaller particle size could give greater $\mathrm{P}_{\max }$ and $(\mathrm{dP} / \mathrm{dt})_{\max }$ values, the surface area-to-volume ratio must be taken into consideration. From the test, it showed that the particle size of $160 \mu \mathrm{m}$ was the optimum size of tea dust that could generate high $\mathrm{P}_{\max }$ and $(\mathrm{dP} / \mathrm{dt})_{\max }$. Eckhoff [24] stated that for most organic materials, a further decrease in particle size will no longer increase the combustion rate as the devolatilization no longer controls the explosion rate. This explains why the particle size of 125 $\mu \mathrm{m}$ has the lowest $\mathrm{P}_{\max }$ and $(\mathrm{dP} / \mathrm{dt})_{\max }$ although the size is the smallest.

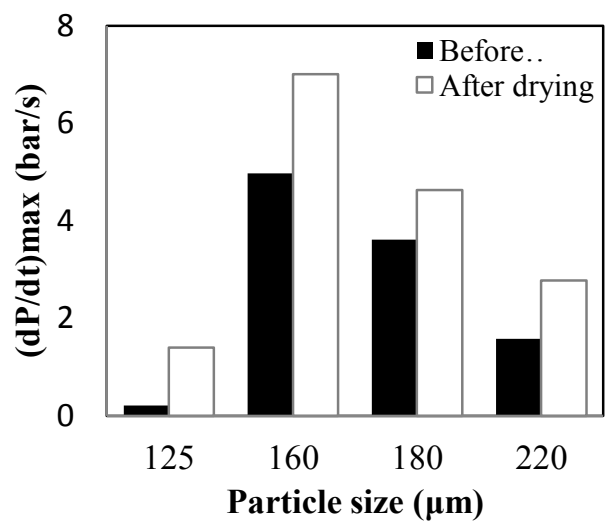

Fig. 3. Graph of $(\mathrm{dp} / \mathrm{dt})_{\max }$ versus Various Particle Sizes

\subsubsection{Deflagration Index, $K_{S t}$}

Besides $\mathrm{P}_{\max }$, another property to determine the explosion severity is $\mathrm{K}_{\mathrm{St}}$. The value determines the normalized rate of pressure rise of a combustible rise.
The relationship of deflagration index and maximum overpressure was calculated by using the equation below, which is known as cubic's law:

$$
\mathrm{K}_{\mathrm{St}}=(\mathrm{dP} / \mathrm{dt})_{\max } \cdot \mathrm{V}^{1 / 3}
$$

Where $\mathrm{V}$ is the volume of the vessel and $(\mathrm{dP} / \mathrm{dt})_{\max }$ is the rate of pressure rise.

$\mathrm{K}_{\mathrm{St}}$ represents the maximum mass burning rate and corresponds to the time in the explosion when the flame area is at its maximum. Generally, $\mathrm{K}_{\mathrm{St}}$ would increase with the increase of $\mathrm{P}_{\max }$. Based on Table 2, the value of $\mathrm{K}_{\mathrm{St}}$ before drying is $5.70 \mathrm{bar} . \mathrm{m} / \mathrm{s}$ for $125 \mu \mathrm{m}, 134.88$ bar.m/s for $160 \mu \mathrm{m}, 97.99$ bar.m/s for $180 \mu \mathrm{m}$ and 42.75 bar.m/s for $220 \mu \mathrm{m}$. After drying, the $\mathrm{K}_{\mathrm{St}}$ value increased to $38.00 \mathrm{bar} . \mathrm{m} / \mathrm{s}, 190.31 \mathrm{bar} / \mathrm{m} . \mathrm{s}, 125.62 \mathrm{bar} . \mathrm{m} / \mathrm{s}$ and $75.33 \mathrm{bar} . \mathrm{m} / \mathrm{s}$, respectively. The result shows that tea dust at $160 \mu \mathrm{m}$ has the highest $\mathrm{K}_{\mathrm{St}}$ for both before and after drying.

Table 2. $\mathrm{K}_{\mathrm{St}}$ value from different tea size for both before and drying conditions

\begin{tabular}{|c|c|c|}
\hline \multirow{2}{*}{ Particle size $(\boldsymbol{\mu m})$} & \multicolumn{2}{|c|}{$\mathbf{K}_{\mathbf{S t}}(\mathbf{b a r} \mathbf{m} / \mathbf{s})$} \\
\cline { 2 - 3 } & Before drying & After drying \\
\hline 125 & 5.70 & 38.00 \\
\hline 160 & 134.88 & 190.31 \\
\hline 180 & 97.99 & 125.62 \\
\hline 220 & 42.75 & 75.33 \\
\hline
\end{tabular}

The flame propagation during dust explosion starts with devolatilization before speeding to vapour phase combustion, which replicates the gas explosion mechanism. From the TGA result discussed earlier, tea dust at $160 \mu \mathrm{m}$ has a larger surface area and more volatile than $180 \mu \mathrm{m}$ and $220 \mu \mathrm{m}$. Ammyotte et al. [25] stated that with the increase of volatile content, the hazard posed is more dramatic. This suggested that dust with high volatility could give a higher value of $\mathrm{K}_{\mathrm{St}}$ and thus high severity of the dust explosion. Besides, $\mathrm{K}_{\mathrm{St}}$ decreases linearly with increasing of moisture content. The water may inhibit the explosibility and severity of the particles and tends to lower the ignition sensitivity of the materials. This explained why the particle size of 180 $\mu \mathrm{m}$ and $220 \mu \mathrm{m}$ have lower $\mathrm{K}_{\mathrm{St}}$ as their moisture content are higher than the particle size $125 \mu \mathrm{m}$ and $160 \mu \mathrm{m}$.

Since the range of the tea dust is above $0-200$ bar.m/s, it fell in class St1. According to OSHA [26], most of the food-based dust are class St1. Research work has been done by Ramírez et al. [23] on the materials such as wheat grain dust and alfalfa have $\mathrm{K}_{\mathrm{St}}$ value of $148 \mathrm{bar} . \mathrm{m} / \mathrm{s}$ and $50 \mathrm{bar} . \mathrm{m} / \mathrm{s}$ respectively. Even though the class are the same, however, the moisture content and the particle size did not match with the tea dust sample in this research. Although these materials are class St 1, those $\mathrm{K}_{\mathrm{St}}$ values could create adequate power to cause a flash fire, compromise containment on a piece of equipment or blow out the walls of a building as mentioned by Dastidar et al. [27]. 


\section{Conclusion}

This paper emphasized the effect of tea size on dust explosion severity. The experiment was done in a $20 \mathrm{~L}$ spherical vessel over different particle sizes at $125 \mu \mathrm{m}$, $160 \mu \mathrm{m}, 180 \mu \mathrm{m}$ and $220 \mu \mathrm{m}$. The following are the conclusions of this study:

(i) As the particle size increases, the surface area of the particle decreases, the moisture content increases, the volatility decreases and the ash content increases.

(ii) The results showed that the values of $\mathrm{P}_{\max }$ and $(\mathrm{dP} / \mathrm{dt})_{\max }$ of tea dust were more severe for the particle size of $160 \mu \mathrm{m}$ for which are 1.97 bar and $4.97 \mathrm{bar} / \mathrm{s}$ respectively before drying and $2.09 \mathrm{bar}$ and $7.01 \mathrm{bar} / \mathrm{s}$ respectively after drying.

(iii) Low moisture content would be the main reason contributing to higher $\mathrm{K}_{\mathrm{St}}$ of the dust. The high volatility of dust could give a higher value of $\mathrm{K}_{\mathrm{St}}$ hence the high severity of the dust explosion. As the moisture content decrease, the mass of dust particles decrease and thus increase their ability to remain fugitive in the air and to contribute to dust distribution and layering.

(iv) Since the $\mathrm{K}_{\mathrm{St}}$ value for tea dust is between $0-200$ bar.m/s, it falls in Class St 1.

The authors would like to thank Universiti Malaysia Pahang for supporting this study financially under UMP grant (PGRS180391).

\section{References}

1. NFPA, Standard on explosion prevention systems (2002)

2. X. Yan, J. Yu, Powder Technol. Dust explosion venting of small vessels at the elevated static activation overpressure, 261, 250-256 (2014)

3. J. Taveau, Process Saf. Prog, Secondary dust explosions: How to prevent them or mitigate their effects, 31, 36-50 (2012)

4. M. Adnan, A. Ahmad, A. Ahmed, N. Khalid, I. Hayat, I. Ahmed, Pak. J. Bot. Chemical compositions and sensory evaluation of tea (Camellia Sinensis), 45, 901-907 (2013)

5. C. Proust, A. Accorsi, L. Dupont, J. Loss Prevent Proc. Measuring the violence of dust explosions with the 20L sphere and with the standard ISO $1 \mathrm{~m}^{3}$ vessel: systematic comparison and analysis of the discrepancies, 20, 599-606 (2007)

6. O. Dufaud, M. Traore, L. Perrin, S. Chazelet, D. Thomas, J. Loss Prevent Proc. Experimental investigation and modelling of aluminium dust explosions in the 20 L sphere, 23, 226-236 (2010)

7. R. Dobashi, Fire Saf. J. Studies on accidental gas and dust, 91, 21-27 (2017)

8. R. Eades, K. Perry, C. Johnson, J. Miller, Int. J. Min. Sci. Technol. Evaluation of the $20 \mathrm{~L}$ dust explosibility testing chamber and comparison to a modified 38 L vessel for underground coal, $\mathbf{2 8}$, 885-890 (2018)

9. A. Benedetto, A. Garcia, P. Russo, Ind. Eng. Chem. Res. Combined effect of ignition energy and inertial turbulence on the explosion behaviour of lean gas/dust-air mixtures, 51, $772-779$ (2012)

10. J. Wade, G. Martin, D. Long, Powder Technol. A methodological approach for determining the effect of moisture content on the compaction properties of powders: granular hydroxyapatite, 246, 511-519 (2013)

11. B. Du, J. Tan, W. Huang, N. Kuai, J. Yuan, Z. Li, Y. Gan, Effect of ignition energy on dust explosion behavior: Phenomena of under-driving and overdriving (2012)

12. T. Abbasi, S. Abbasi, J. Hazard Mater. Dust explosions cases, causes, consequences and control, 140, 7-44 (2009)

13. M. Todaka, W. Kowhakul, H. Masamoto, M. Shigematsu, J. Loss Prevent Proc. Thermal analysis and dust explosion characteristics of spent coffee grounds and jatropha, 44, 538-543 (2016)

14. L. Cashdollar, J. Loss Prevent Proc. 13 (2000)

15. A. Fumagalli, M. Derudi, R. Rota, S. Copelli, J. Loss Prevent Proc, 44, 311-322 (2016)

16. S. Bershad, 20L sphere data - agricultural dusts (NFPA, 2014)

17. S. Lemkowitz, A. Pekalski, H. Pasman, J. Zevenbergen, J. Phys. Iv. How the combination of chemistry and engineering determine dust and gas explosion behaviour: Educating science and engineering students and training industrial professionals in practical gas and dust explosion theory, 12, 197-198 (2002)

18. M. Lemkowitz, H. Pasman, KONA Powder Part. J. $A$ review of the fire and explosion hazards of particulates, 31, 53-81 (2014)

19. K. Lee, H. Kim, K. Chu, K. Ko, Sci. Technol. Energ. Ma. The generation characteristics of instant dusts at the time of structure demolition by explosion, 72, 26-35 (2011)

20. E. Inoka, J. Sapko, L. Marcia, A. Isaac, S. Eric, J. Loss Prevent Proc. Design and development of a dust dispersion chamber to quantify the dispersibility of rock dust, 39, 7-16 (2016)

21. M. Suhaimi, A. Saat, M. Wahid, M. Sies, J. Technol. Flame propagation and burning rates of methane-air mixtures using schlieren photography, 78, 21-27 (2016)

22. A. Dahoe, J. Zevenbergen, S. Lemkowitz, B. Scarlett, J. Loss Prevent Proc. Dust explosions in spherical vessels: the role of flame thickness in the validity of the cube-root law, 9, 33-44 (1996)

23. A. Ramirez, J. Garcia-Torrent, J. Aguado, J. Hazard Mater. Determination of parameters used to prevent ignition of stored materials and to protect against explosions in food industries, 168, 115-120 (2009)

24. K, Eckhoff, Dust Explosions in the process industries, 385-430 (2003) 
25. P. Amyotte, M. Lindsay, R. Domaratzki, N. Marchand, A. Di Benedetto, P. Russo, Process Saf. Prog. Prevention and mitigation of dust and hybrid mixture explosions, 29, 17-21 (2010)

26. OSHA, Hazard alert: Combustible dust explosions (2008)

27. A. Dastidar, P. Amyotte, J. Going, K. Chatrathi, Fuel, Inerting of coal dust explosions in laboratory and intermediate-scale chambers, 80, 1593-1602 (2001) 